\title{
In Vitro Activity of Lawsonia inermis (Henna) on Some Pathogenic Fungi
}

\author{
Elham Abdelbasit Suleiman ${ }^{1}$ and Elbasheir Ahmed Mohamed ${ }^{2}$ \\ ${ }^{1}$ Veterinary Research Institute, P.O. Box 8067, Amarat, Khartoum, Sudan \\ ${ }^{2}$ Faculty of Medical Laboratories Science, Omdurman Islamic University, Sudan \\ Correspondence should be addressed to Elham Abdelbasit Suleiman; elham842001@yahoo.com
}

Received 25 May 2014; Revised 18 August 2014; Accepted 2 September 2014; Published 23 September 2014

Academic Editor: Terezinha Inez Estivalet Svidzinski

Copyright (C) 2014 E. A. Suleiman and E. A. Mohamed. This is an open access article distributed under the Creative Commons Attribution License, which permits unrestricted use, distribution, and reproduction in any medium, provided the original work is properly cited.

\begin{abstract}
The present study was conducted to investigate antifungal activity of Lawsonia inermis (Henna plant). Leaf samples of the plant were collected from Eastern Nile of Khartoum State, Sudan. Ethanol and petroleum ether extracts were obtained by maceration (cold method). The extracts were bioassayed in vitro to know their bioactivity to inhibit the growth of tested fungi. The cup-plate agar diffusion method was adopted to assess the antifungal activity of the extracts against tested yeasts, while agar incorporated method was used for other molds. Both extracts revealed antifungal activity against all yeast strains except Pichia fabianii which was found resistant to both ethanol and ether extracts. The results displayed antifungal activity against tested fungi. Minimum inhibition concentration (MIC) of $5,7.5$, and $10 \mathrm{mg} / \mathrm{mL}$ was found to inhibit the growth of tested dermatophytes. The obtained results revealed antifungal activity of Henna leaves extracts which support the traditional use of Henna in therapy of fungal infections. The possibility of therapeutic use of Sudanese Henna as antifungal agent is recommended.
\end{abstract}

\section{Introduction}

Plants have been used to treat humans, animals, and plant diseases from time immemorial. Herbal medicines have been known to man for centuries [1]. Henna plant, Lawsonia inermis Linn, is such a plant known for healing attributes and is now the subject of intense scientific study [2]. Though it was used for various purposes, the antifungal property was not yet investigated. Thus the present study was conducted to evaluate its antifungal potential. Lawsonia inermis (Henna) is an ornamental evergreen plant cultivated in the tropics [3]. It belongs to the family Lythraceae. In Sudan it is traditionally used to develop a red or black coloring to hands, feet, and hair in some occasions such as weddings and religious festivals.

The phytochemical analysis of the plant leaves revealed the presence of anthroquinones as major constituents which are commonly known to posses antimicrobial activity [4]. Ethyl acetate extract of Lawsonia inermis was found to be active against all bacteria tested [5]. Screening of the barks of 30 plant species against Microsporum gypseum and Trichophyton mentagrophytes showed that only L. inermis
L. extract exhibited absolute toxicity. The extract showed broad fungicidal spectrum when tested against 13 ring worm fungi [6]. The present study was conducted to evaluate the antifungal potential of Lawsonia inermis leaf extracts.

\section{Materials and Methods}

2.1. Henna Plant. Home-grown (Lawsonia inermis Linn) Henna leaves were collected from El Bakrab village east of the Blue Nile, Khartoum State, Sudan. The plant was identified and authenticated by the experts of Medicinal and Aromatic Plants Research Institute (MAPRI). Voucher specimen has been deposited at the Herbarium of MAPRI.

2.2. Microorganisms. Candida albicans (ATCC 7596) was obtained from National Centre for Research (Sudan) and the clinical isolates of Pichia fabianii, Saccharomyces cerevisiae, Aspergillus flavus, Scopulariopsis brevicaulis, Trichophyton mentagrophytes, Trichophyton violaceum, Trichophyton verrucosum, and Phialophora richardsiae were obtained from 
the Mycology Department, Central Veterinary Research Institute, Soba, Khartoum, Sudan.

2.3. Preparation of Crude Extracts. Leaves of Lawsonia inermis (Henna) were dried in the shade. $150 \mathrm{~g}$ of powdered leaves was extracted in soxhlet apparatus with petroleum ether $60-80^{\circ} \mathrm{C}$ and $170 \mathrm{~g}$ of powdered leaves was extracted with $80 \%$ ethanol using maceration method [7]. Serial dilutions of the extracts were prepared to determine MIC. Dimethyl sulfoxide (DMSO) and petroleum ether were used as negative controland ketoconazole and Nystatin were used as positive control.

2.4. Preparation of Stock Drug Solution (Ketoconazole). Stock drug solution $(1280 \mathrm{mg} /$ liter $)$ was prepared by adding $50 \mathrm{~mL}$ of dimethyl sulfoxide to $64 \mathrm{mg}$ of ketoconazole and allowed to stand for $30 \mathrm{~min}$. It was then dispensed in small amount and stored at $-20^{\circ} \mathrm{C}$ until used [8].

\subsection{In Vitro Assay of Antimicrobial Activity of the Extracts}

2.5.1. The Cup-Plate Agar Diffusion Method. The cup-plate agar diffusion Hadecek and Greger [9] method was adopted with some minor modifications to assess the antifungal activity of the prepared extracts. One gram of each extract was weighed and dissolved in $5 \mathrm{~mL}$ of the solvent used for the extraction to give $200 \mathrm{mg} / \mathrm{mL}$. The microorganisms were standardized according to the $0.5 \mathrm{McF}$ arland scale. $100 \mu \mathrm{L}$ of the stock solution was thoroughly mixed with $20 \mathrm{~mL}$ molten sterile Sabouraud dextrose agar and maintained at $25^{\circ} \mathrm{C}$. The agar plates were left to set and in each of these plates 4 cups $(10 \mathrm{~mm}$ in diameter) were cut using a sterile cork borer (Number 4 ) and agar discs were removed. Cups were filled with $0.2 \mathrm{~mL}$ of each extract using automatic microlitre pipette and allowed to diffuse at room temperature for two hours. The plates were then incubated in the upright position at $37^{\circ} \mathrm{C}$ for 2-3 days. Activity of each extract was tested in triplicate. The diameters of zones of inhibition were measured in millimeter using a transparent well calibrated ruler, averaged and the mean values were tabulated. Results of the qualitative screening were recorded as the average diameter of the growth inhibition zone surrounding the wells containing the extract [10].

2.5.2. Agar Incorporation Technique. The antifungal susceptibility of the extracts and the standard drugs ketoconazole and Nystatin were determined using agar incorporation technique. Concentrations of 50, 100, and $200 \mathrm{mg} / \mathrm{mL}$ of the extracts were tested. The test organisms were inoculated onto Sabouraud dextrose agar (SDA) supplemented with chloramphenicol $(0.05 \mathrm{mg} / \mathrm{mL})$ for yeasts and SDA supplemented with chloramphenicol and cycloheximide $(0.5 \mathrm{mg} / \mathrm{mL})$ for dermatophytes. Each plate was inoculated with the test organism. The control group was inoculated with the same organism. All plates were incubated at $25^{\circ} \mathrm{C}$ for three to seven days except for dermatophytes which were incubated for up to three weeks at the same temperature [8]. Plates were observed for the presence or inhibition of growth. Negative control (ethanol and petroleum ether) and positive control (Nystatin and ketoconazole) were run in the same manner parallel to the treatment. The test was performed in triplicate.

\subsection{Minimum Inhibitory Concentration (MIC) Determina-} tion. The MIC of the ethanol extract against tested microorganisms was determined by the macrobroth dilution method [8]. Stock solution of the extract at a concentration of $200 \mathrm{mg} / \mathrm{mL}$ was prepared by serial two-fold dilutions in Sabouraud's broth. The tubes were then inoculated with $100 \mu \mathrm{L}$ of cultures $\left(10^{7}\right.$ cells). Uninoculated tubes containing growth medium and extract were used as controls. The tubes were then incubated at appropriate temperatures for 48 hours. The MIC was defined as the lowest concentration that completely inhibited the growth of the organism.

2.7. Statistical Analysis . Results were expressed as mean \pm $\mathrm{SD}$. The significant difference between means was determined using one-way analysis of variance (ANOVA). Statistical significance was established at $P<0.05$.

\section{Results}

The current investigation showed that Henna plant possesses good antimicrobial activity against tested fungi. The obtained results demonstrated antifungal activity of both extracts. The cup-agar diffusion method revealed antifungal activity of the extract against yeasts and mould demonstrated by area of inhibition zone around the wells, while inhibition of growth revealed antifungal activity against dermatophytes. The ethanol extract has shown significant activity against yeasts compared to petroleum ether extract. The inhibition zone induced by ethanol extract at the concentration of $10 \mathrm{mg} / \mathrm{mL}$ was found to be $26.3 \pm 3 \mathrm{~mm}$ against Saccharomyces cerevisiae and $17 \pm 0 \mathrm{~mm}$ against Candida albicans.

Petroleum ether extract exhibits antifungal activity to $S$. cerevisiae with mean inhibition zone equal to $25.3 \pm 0.6 \mathrm{~mm}$ at a concentration of $10 \mathrm{mg} / \mathrm{mL}$ and $22.7 \pm 0.6 \mathrm{~mm}$ to $C$. albicans which is greater than that shown for the commercial Nystatin $(17 \pm 0 \mathrm{~mm})$. It was noted that both extracts showed no antifungal activity to Pichia fabianii (Table 1, Figures 1 and 2).

Significant antifungal effect expressed as MIC of ethanol extract against tested dermatophytes was shown (Table 2). Trichophyton mentagrophytes and T. violaceum were found more sensitive to ethanol extract with MIC of $7.5 \mathrm{mg} / \mathrm{mL}$. However, all Trichophyton species were found sensitive to ethanol at a concentration of $10 \mathrm{mg} / \mathrm{mL}$ (Figure 3).

The ethanol extract displayed fungicidal activity to tested moulds at a concentration of $5 \mathrm{mg} / \mathrm{mL}$ and fungi static activity to Aspergillus flavus at a concentration of $10 \mathrm{mg} / \mathrm{mL}$ (Table 3, Figures 4, 5, and 6).

\section{Discussion}

The antifungal activity of $L$. inermis leaf extracts has been evaluated in vitro against $C$. albicans, S. cerevisiae, and some selected dermatophytes. The effect was found to be dose 
TABLE 1: Antimicrobial activity of Lawsonia inermis, ethanol, and petroleum ether leaf extracts against yeasts.

\begin{tabular}{lcccc}
\hline Extract & Concentration $\left(\mathrm{mg} / \mathrm{mL}^{-1}\right)$ & S. cerevisiae & $\begin{array}{c}\text { C. albicans } \\
\text { Diameter of inhibition zone }(\mathrm{mm})\end{array}$ & P. fabianii \\
\hline Ethanol & 100 & $23.3 \pm 1.5$ & $16.7 \pm 0.6$ & 0 \\
Ethanol & 200 & $26.3 \pm 3.2$ & $17 \pm 0$ & 0 \\
Petroleum ether & 100 & $24.7 \pm 0.6$ & $21.3 \pm 0.6$ & 0 \\
Petroleum ether & 200 & $25.3 \pm 0.6$ & $22.7 \pm 0.6$ & 0 \\
\hline
\end{tabular}

Data are presented as mean \pm SD of zone of inhibition $(\mathrm{mm})$; inhibition zones are the mean of three replicates; $S$ (Saccharomyces); C (Candida); P (Pichia).

TABLE 2: MIC of ethanol extract of Lawsonia inermis leaf against dermatophytes.

\begin{tabular}{lccccc}
\hline Extract & Concentration $(\mathrm{mg} / \mathrm{mL})$ & T. mentagrophytes & T. verrucosum & T. violaceum & Ketoconazole \\
\hline & 2.5 & + & + & + & - \\
Ethanol extract & 5.0 & + & + & - & - \\
& 7.5 & - & + & - \\
\hline
\end{tabular}

Sympols (+) indicates growth of fungi; $(-)$ indicates inhibition of growth.

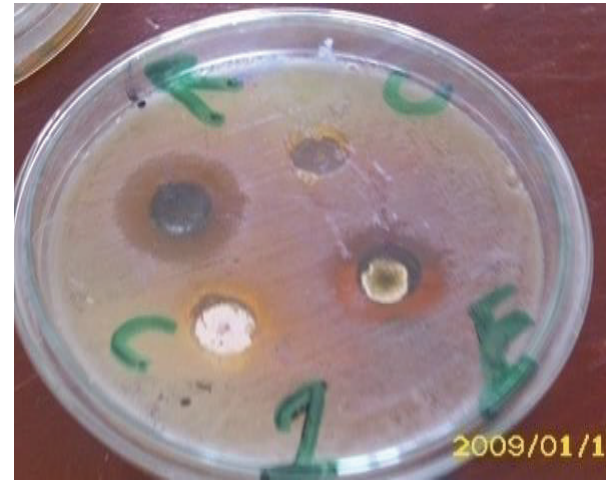

FIGURE 1: Inhibition zone of C. albicans. C: ethanol as negative control; R: ether extract; E: ethanol extract.

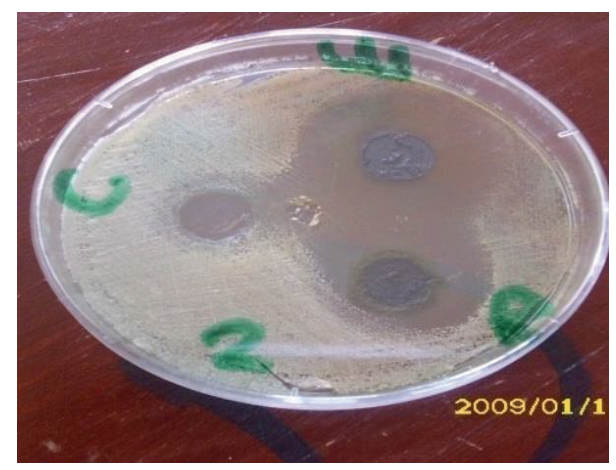

FIGURE 2: Inhibition zone of S. cerevisiae. C: ethanol as negative control; R: ether extract; E: ethanol extract.

dependent. Petroleum ether extract showed a wide antifungal spectrum compared to ethanol extract against tested yeasts. It exhibited inhibition zone wider than the commercial Nystatin. Therefore, petroleum ether is a better solvent for consistent extraction of antifungal substances from $L$. inermis plant. Inhibion of growth of C. albicans shown in the present study was consistent with that reported by Maher and his collaborators [11] where ethanol extract of Ruta chalepensis revealed similar inhibition zone of $17 \mathrm{~mm}$. But S. cerevisiae was found to be more sensetive to ethanol extract at the concentration of $10 \mathrm{mg} / \mathrm{mL}$ compared to C. albicans. This shows spesies susceptibility to the extrcat used. Furthermore, all tested moulds were found to be sensitive to ethanol extract at a concentration of $5 \mathrm{mg} / \mathrm{mL}$ except Aspergillus flavus. This indicates less sensitivity of the extract to $A$. flavus.

In the present study, all tested dermatophytes showed great sensitivity to ethanol extract where complete inhibition of growth was observed. This finding is similar to those obtained in some previous studies [12] where $100 \%$ inhibition of Trichophyton mentagrophytes growth was observed on using $10 \mathrm{mg} / \mathrm{mL}$ of $L$. inermis ethanol extract. This indicates great sensitivity of dermatophytes to L. inermis plant. Thus further research on mode of action of such novel plant is recommended.

The phytochemical screening of Sudanese Henna plant revealed naphthoquinone as an active ingredient that might display the antifungal activity against tested fungi [4]. Previous studies $[6,13]$ disclosed the same result when they screened the antifungal activity of higher plants; leaves of L. inermis were found to exhibit strong fungicidal effect due to naphthoquinone which was found to be the main active ingredient. Furthermore, the presence of tannin might play a vital role as antimicrobial agent as suggested by Banerjee and his collaborators [14].

\section{Conclusions}

Ethanol and petroleum ether leaf extracts of $L$. inermis (Henna) revealed antimycotic activity against tested fungi. With the ever increasing resistant strains of microorganisms to the already available and synthesized antifungal drugs, the naturally available Lawsonia inermis (Henna) could be a potential alternative. Since our study was carried out using 


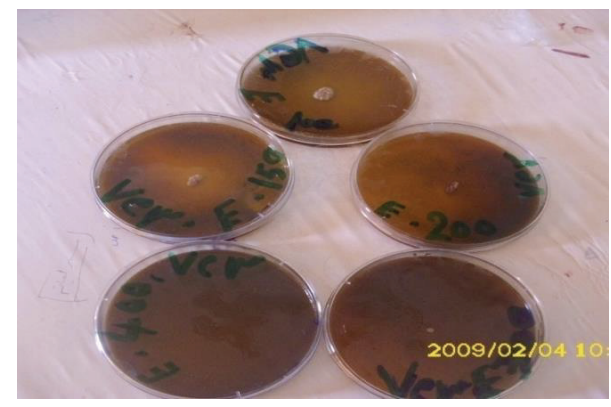

(a)

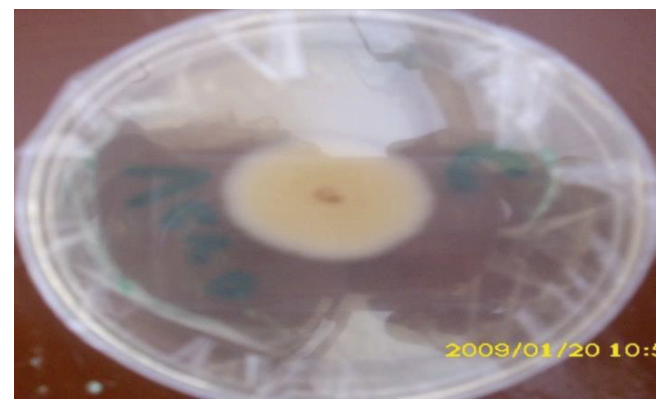

(b)

Figure 3: Control plate (b) showing growth of T. verrucosum and growth inhibition of T. verrucosum in ethanol extract of $L$. inermis leaves (a) at different concentrations after 10 days of incubation at $37^{\circ} \mathrm{C}(\times 40)$.

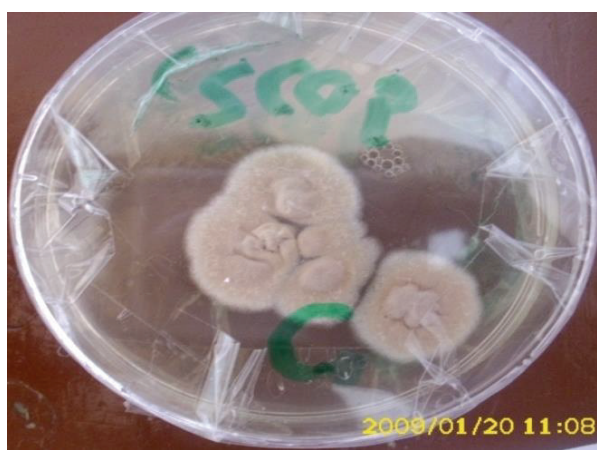

(a)

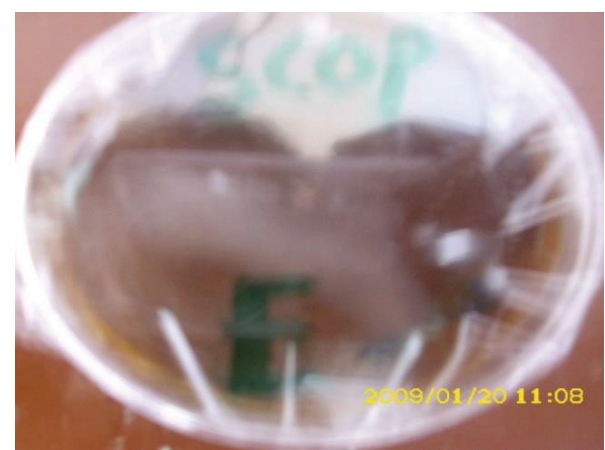

(b)

Figure 4: Control plate of Scopulariopsis brevicaulis (a) and ethanol-treated plate (b) at a concentration of $10 \mathrm{mg} / \mathrm{mL}$ ethanol extract of $L$. inermis after 7 days of incubation at room temperature $(\times 40)$.

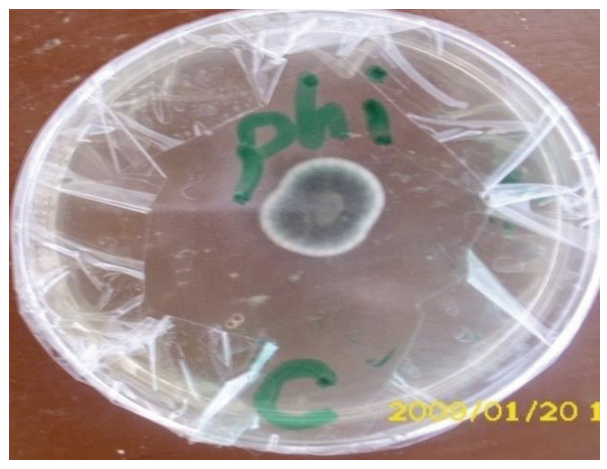

(a)

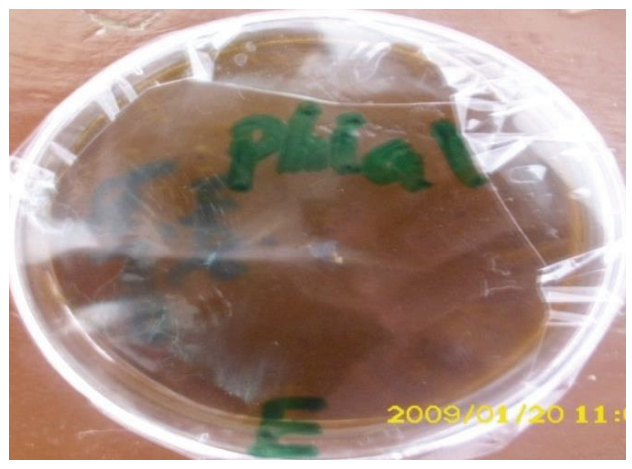

(b)

FIgURE 5: Control plate of Phialophora richardsiae (a) and ethanol-treated plate (b) at a concentration of $10 \mathrm{mg} / \mathrm{mL}$ ethanol extract of $L$. inermis after 7 days of incubation at room temperature $(\times 40)$.

TABLE 3: Minimun Inhibition Concentration (MIC) of ethanol extract of Lawsonia inermis Leaf against moulds.

\begin{tabular}{|c|c|c|c|c|c|}
\hline Extract & Concentration $(\mathrm{mg} / \mathrm{mL})$ & Aspergillus flavus & Scopulariopsis brevicaulis & Phialophora richardsiae & Dimethyle Sulphoxide \\
\hline \multirow{4}{*}{ Ethanol } & 2.5 & + & + & + & - \\
\hline & 5.0 & + & - & - & - \\
\hline & 7.5 & + & - & - & - \\
\hline & 10 & - & - & - & - \\
\hline
\end{tabular}

Symbols (+) indicates growth of fungi; (-) indicates inhibition of growth. 


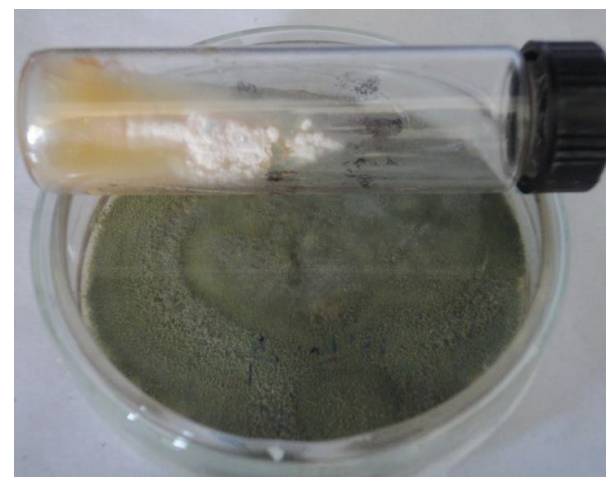

FIgURE 6: White colony of A. flavus on SDA at a concentration of $10 \mathrm{mg} / \mathrm{mL}$ ethanol extract of $L$. inermis showing fungi static activity (vial) and green colony of the control (plate) after 7 days of incubation at room temperature $(\times 40)$.

crude extract, it is necessary to purify the active principle and evaluate its bioactivity for therapeutic application.

\section{Conflict of Interests}

The authors declare that there is no conflict of interests regarding the publication of this paper.

\section{Acknowledgments}

The authors are grateful to Sudan Academy of Science (SAS) for the permission to carry out this study. Great thanks are due to the Staff of Mycology Department, Veterinary Research Institute for technical help.

\section{References}

[1] E. Goun, G. Cunningham, D. Chu, C. Nguyen, and D. Miles, "Antibacterial and antifungal activity of Indonesian ethnomedical plants," Fitoterapia, vol. 74, no. 6, pp. 592-596, 2003.

[2] H. S. Muhammad and S. Muhammad, "The use of Lawsonia inermis linn. (henna) in the management of burn wound infections," African Journal of Biotechnology, vol. 4, no. 9, pp. 934-937, 2005.

[3] K. N. Jallad and C. Espada-Jallad, "Lead exposure from the use of Lawsonia inermis (Henna) in temporary paint-on-tattooing and hair dying," Science of the Total Environment, vol. 397, no. 1-3, pp. 244-250, 2008.

[4] M. A. Abdulmoneim, "Evaluation of Lawsonia inermis Linn. (Sudanese Henna) leaf extract as an antimicrobial agent," Research Journal of Biological Sciences, vol. 2, pp. 417-423, 2007.

[5] N. A. A. Ali, W.-D. Jülich, C. Kusnick, and U. Lindequist, "Screening of Yemeni medicinal plants for antibacterial and cytotoxic activities," Journal of Ethnopharmacology, vol. 74, no. 2, pp. 173-179, 2001.

[6] R. D. Tripathi, H. S. Srivastava, and S. N. Dixit, "A fungitoxic principle from the leaves of Lawsonia inermis Lam," Experientia, vol. 34, no. 1, pp. 51-52, 1978.

[7] J. B. Harborne, Phytochemical Methods, vol. 4, Chapman and Hall, 4, 2nd edition, 1984.
[8] D. W. Warnock, "Methods with antifungal drugs", in Medical Mycology a Practical Approach, E. G. V. Evans and M. D. Richardson, Eds., chapter 11, pp. 235-247, IRL Press, Oxford, UK, 1st edition, 1989.

[9] F. Hadecek and H. Greger, "Testing of antifungal on natural products: methodologies, comparability of results and assay choice," Journal of Analytical Phytochemistry, vol. 11, pp. 137-141, 2000.

[10] F. Kavanah, Analytical Microbiology, vol. 11, Academic Press, New York, NY, USA, 1972.

[11] M. Obeidat, M. Shatnawi, M. Al-alawi et al., "Antimicrobial activity of crude extracts of some plant leaves," Research Journal of Microbiology, vol. 7, no. 1, pp. 59-67, 2012.

[12] M. M. Zakaria, "The inhibitory effect of Lawsonia inermis leaves on some fungi," Irag Academic Scientific Journal, vol. 10, no. 4, pp. 501-510, 2010.

[13] V. Natarajan, P. V. Venugopal, and T. Menon, "Effect of Azadirachta indica (neem) on the growth pattern of dermatophytes," Indian Journal of Medical Microbiology, vol. 21, no. 2, pp. 98-101, 2003.

[14] S. Banerjee, A. Das, P. Chakraborty, K. Suthindhiran, and M. A. Jayasri, "Antioxidant and antimicrobial activity of Araucaria cookii and Brassaia actinophyla," Pakistan Journal of Biological Sciences, vol. 17, no. 5, pp. 715-719, 2014. 

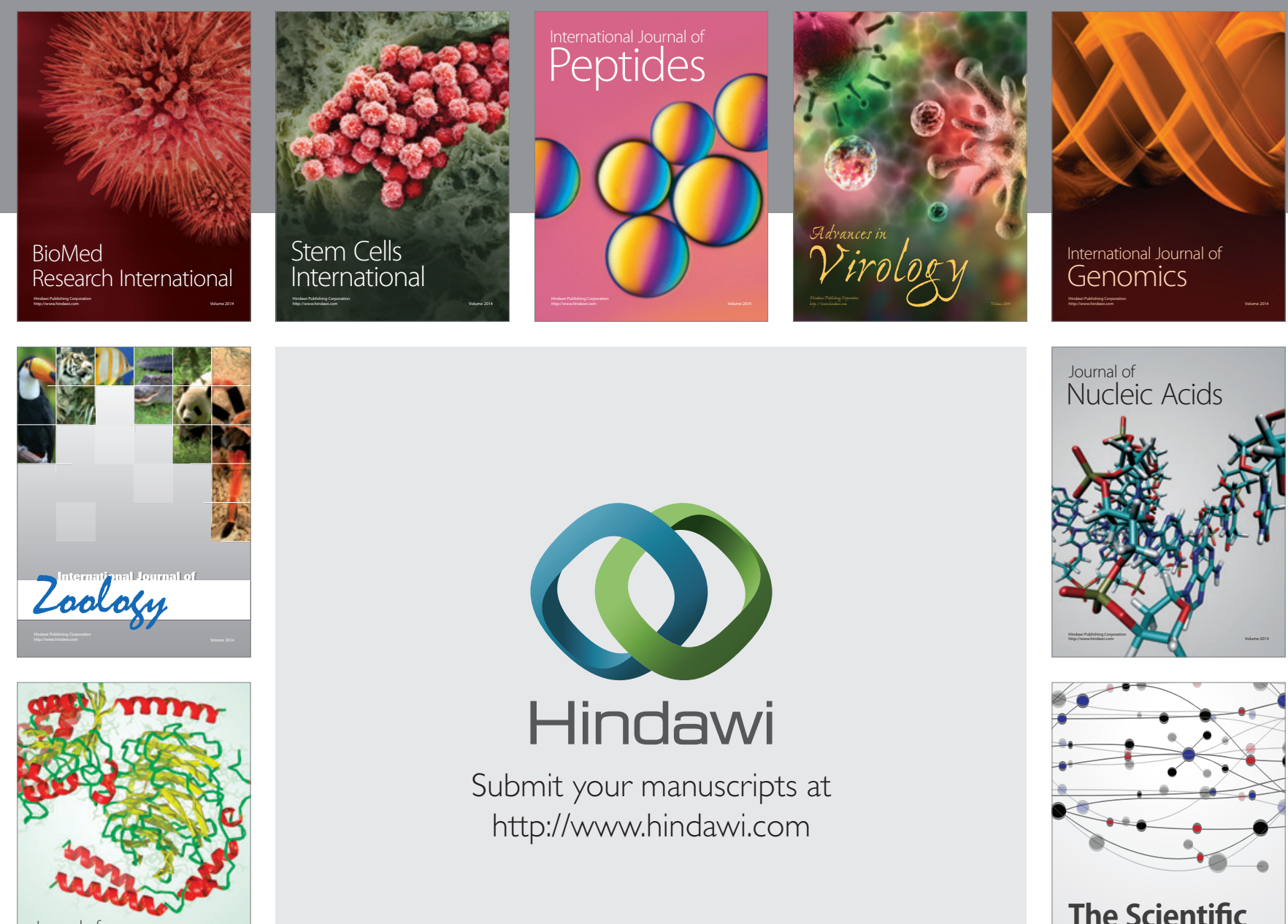

Submit your manuscripts at

http://www.hindawi.com

Journal of
Signal Transduction
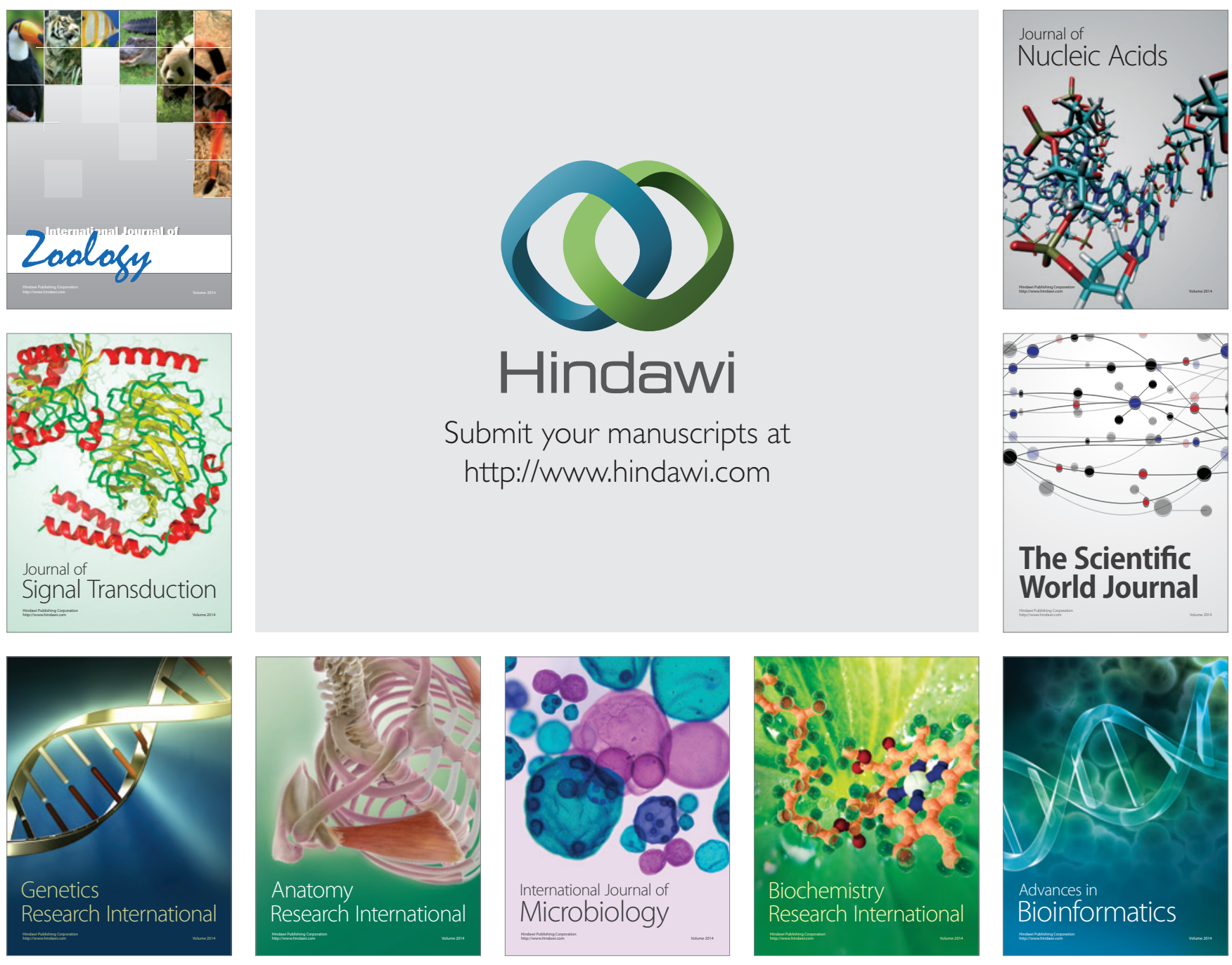

The Scientific World Journal
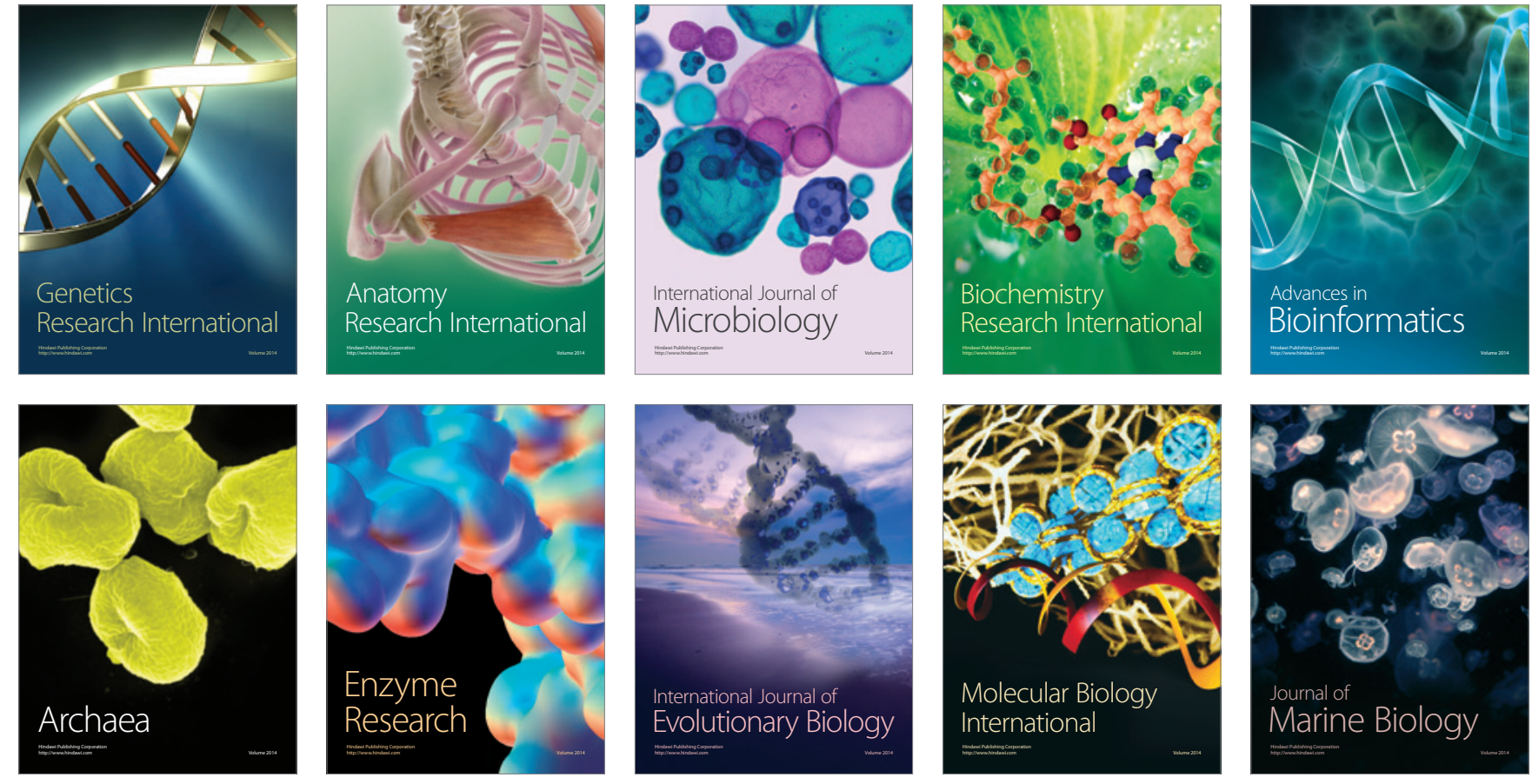